\title{
VIBRATION REDUCTION COUNTERMEASURES OF RAILWAY CONCRETE VIADUCT
}

\author{
Tsutomu Watanabe ${ }^{1, a}$, Koudai Matsuoka ${ }^{1}$, Munemasa Tokunaga ${ }^{1}$, Masamichi Sogabe ${ }^{2}$ \\ ${ }^{1}$ Railway Technical Research Institute, Structural Mechanics Laboratory Railway Dynamics Division, Tokyo, Japan \\ ${ }^{2}$ Railway Technical Research Institute, Railway Dynamics Division, Tokyo, Japan
}

\begin{abstract}
In this paper, numerical experiments about the structure borne sound countermeasures were conducted, by paying attention to the structure vibration of RC girder. Numerical experiments for the vehicle/track system model was carried out using the DIASTARSIII program, developed by the Railway Technical Research Institute, which analyzes dynamic interaction between the vehicle and railway structure. Also, numerical analysis for the track/structure system model was carried out using the DIARIST program for the track structure. As a result, we elucidated the vibration reduction effect of various countermeasures. First, vibration reduction effect of soft track pad of $30 \mathrm{MN} / \mathrm{m}$ is recognized in the frequency band above about $70 \mathrm{~Hz}$ by measurement results and analysis results. Second, the frequency band which obtained reduction effect depends a great deal on natural frequency of vibrationreducing track.
\end{abstract}

\section{Introduction}

Structure born sound is generated as a result of a varying acting force (hereafter called an "excitation force") caused by a railway train running on track irregularity of the order of several micrometers, always existing on the surfaces of the wheel treads and the rail heads, and also by track displacement that has a wavelength of the order of several meters in the direction of the railway track, causing the wheels and the rails to vibrate. This vibration is transmitted to the track consisting of sleepers and track slabs, and also to the structure (girder bridges, viaducts, truss bridges and so on) that supports the track, causing sound to be radiated from the vibrating surfaces of the various members. Structure born sound generated from concrete rigid frame viaducts or other types of concrete bridges is mainly comprised by the frequency components in the range between several tens of $\mathrm{Hz}$ to $1000 \mathrm{~Hz}$. In the case of a high-speed railway the dominant zone in this frequency range lies between 30 and $100 \mathrm{~Hz}$.

In order to reduce the structure borne sound, it is effective to conduct the rail and wheel grinding, to reduce train weight and to use low elastic rail fastening systems and vibration-reducing track.

Although, the vibration-reducing track with a small constant of track-supporting spring is predicted to have a large deformation and there is a concern that it may generate resonance, which consequently degrades running safety and ride comfort of a train, by numerical experiments, we confirmed that it is possible to improve the running safety and ride comfort by applying no-joint slab track and uniform elasticity of track-supporting spring [1].

Up until now the authors have developed a numerical analysis model for vibration up to about $200 \mathrm{~Hz}$ generated from RC rigid frame viaduct which is the cause of structure born sound, and have first carried out studies focusing on the various parameters of the structure in the overall system composed of vehicle/track/structure [2]. In this research, we focus on various track structures, and we conducted numerical experiments for the structure borne sound countermeasures, by paying attention to the structure vibration of RC girder.

\section{Research methods}

\subsection{Analysis methods}

Figure 1 shows the outlines of the structure to be analyzed, and Table 1 shows material constants for each element. We conducted analyses about reinforced concrete standard 3-span RC girder with a length of $20 \mathrm{~m}$.

Figure 2 shows an outline of the analysis model. We have focused on the difference in the dominant frequency band of the vibration mode of the track (mainly lower than $100 \mathrm{~Hz}$ ) and structure (mainly higher than several hundreds $\mathrm{Hz}$ ), and we developed a new method in which the analysis model is divided the system into two parts, namely vehicle/track and track/structure[2]. The vehicle/track model is used for analysis of the excitation force, and then input the excitation force to the track/structure model in order to analysis the vibration of

\footnotetext{
${ }^{a}$ watanabe.tsutomu.30@rtri.or.jp
} 


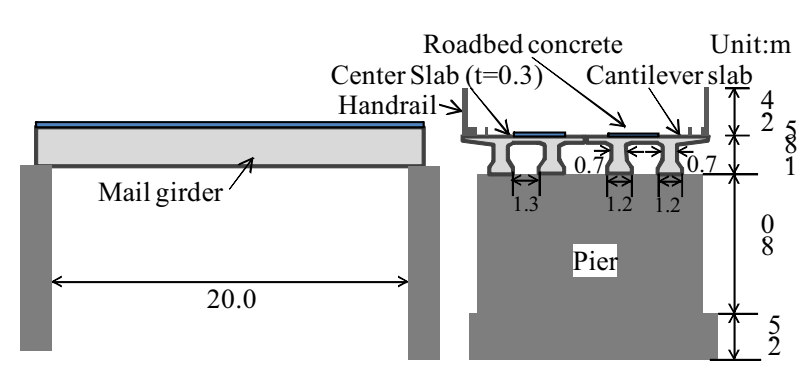

Figure 1. Outlines of the structure

Table 1. Material properties

\begin{tabular}{|c|c|c|}
\hline \multicolumn{2}{|c|}{ Rail } & $60 \mathrm{~kg}$ \\
\hline Spring constant of railpad(MN/m) & 60 \\
\hline \multirow{2}{*}{ Track slab } & dimension(mm) & $4930 \times 2340 \times 190$ \\
\cline { 2 - 3 } & $\begin{array}{c}\text { Young modulus } \\
\left(\mathrm{kN} / \mathrm{mm}^{2}\right)\end{array}$ & 31 \\
\hline \multirow{2}{*}{ CA mortar } & $\begin{array}{c}\text { Young modulus } \\
\left(\mathrm{kN} / \mathrm{mm}^{2}\right)\end{array}$ & 3.5 \\
\cline { 2 - 3 } Concrete & $\begin{array}{c}\text { Thickness(mm) } \\
\text { Young modulus } \\
\left(\mathrm{kN} / \mathrm{mm}^{2}\right)\end{array}$ & 25 \\
\hline Damping Constant (ALL modes) & 25 \\
\hline
\end{tabular}

the structure member. The transfer of the excitation between vehicle/track model and track/structure model is done using a constructed program which automates the pre-processing to the lines of excitation forces. Concretely, the analysis model is separated into two parts on "Lines of Excitation Forces". This enables the numbers of degrees of freedom of analysis to be greatly reduced compared to the case where the entire system is analyzed at one time.

Numerical analysis using the vehicle/track system model was carried out using the DIASTARSIII program, developed by the Railway Technical Research Institute $[3,4]$, which analyzes dynamic interaction between the vehicle and railway structure. Also, numerical analysis using the track/structure system model was carried out using the DIARIST general purpose structure program for the track structure [5].

\subsection{Dynamic model of vehicle}

Figure 3 shows a dynamic model of vehicle, and Figure 4 shows an outline of the axle arrangement of the vehicle. It is assumed that the body, bogies and wheelset are rigid bodies. The model of Figure 3 is a 3-dimensional model in which these rigid bodies are linked by springs $K_{N}$ and dampers $\mathrm{C}_{\mathrm{N}}(\mathrm{N}$ is a suffix in Figure 3 ) according to their respective characteristics. Vehicles have 31 degrees of freedom ( 5 degrees of freedom for the body, 5 degrees of freedom for the bogies, and 4 degrees of freedom for the wheelset). A train is represented by multiple vehicle models linked together by springs $\mathrm{K}_{\mathrm{C}}$ and dampers $\mathrm{C}_{\mathrm{C}}$ attached to the ends of the vehicle models. In this research, the train consisted of six general Shinkansen carriages, each with length of $25 \mathrm{~m}$ and axle load of roughly $60 \mathrm{kN}$.

\subsection{Dynamic model of track and structure}

The track and structure were modeled using the finite element method. In the case of the vehicle/track system

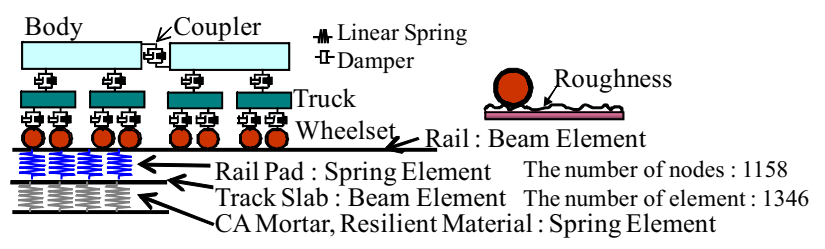

(a) Vehicle/tracks model

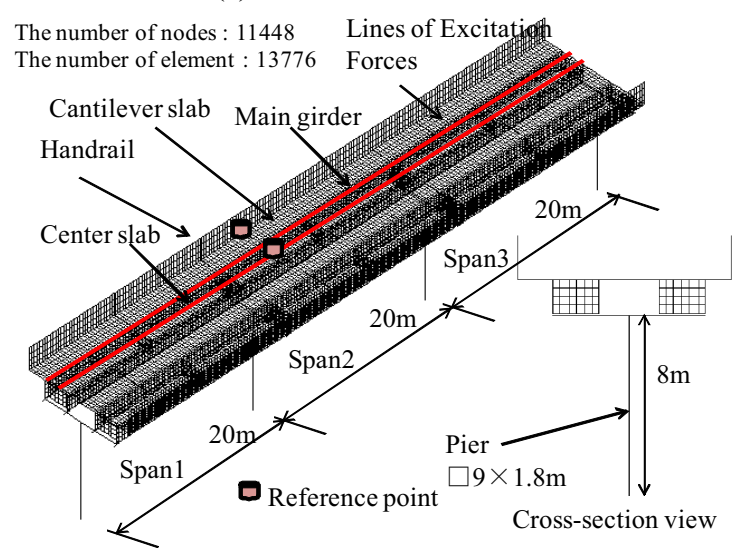

(b) Tracks/structure model

Figure 2. Outlines of the analysis model

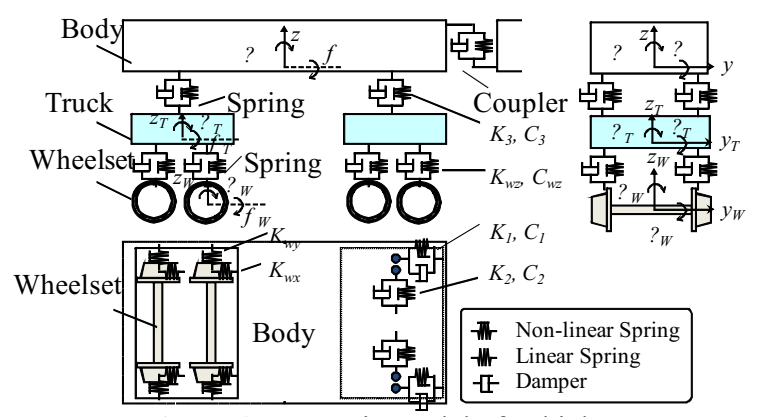

Figure 3. Dynamic model of vehicle.

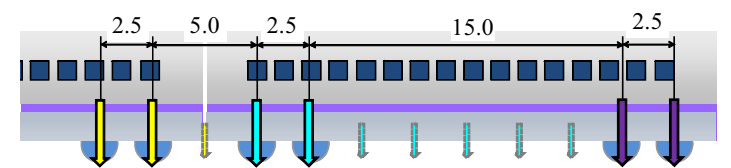

Figure 4. Axle arrangement of vehicle.

model, as shown in Figure 2 (a) the rail and track slabs were modeled using beam elements, and the track pads, resilient material (vibration-reduction track) and the CA mortar (normal slab track) beneath the track slabs were modeled using spring elements. In this model, the spring reaction force equivalent to the resilient materials and the CA mortar was obtained, and the resulting value was input as the excitation force to the "Lines of Excitation Forces", taking into consideration the rail position of the track/structure system model and the load dispersion due to the roadbed concrete, for example. The spring constant of the track pad used in actual analysis was set to three times the nominal value, while making reference to the measurement value of the track spring constant calculated from the results of measuring the displacement of the left and right rails and the axle load. In the case of the track/structure system model, as shown in Figure 2 (b) handrails, cantilever slabs, center slabs and beams were modeled using shell elements, piers were using beam elements. Track members were added to slabs in consideration of weight alone. From a prior study, it was found that the effect on the response of a member in the 
frequency region (roughly above $20 \mathrm{~Hz}$ ) that contributes to structure born sound was small, even when the footing or the ground was modeled. For this reason, it was decided to omit their modeling, and assume that the bottom ends of the piers are fixed.

In the case of both models, the basic mesh size was set to $0.15625 \mathrm{~m}$, which is $1 / 4$ of the rail fastening interval $(0.625 \mathrm{~m})$. In the case of the vehicle/track system model, the total number of nodal point is 1158 and the total number of elements is 1446, while in the case of the track/structure system model, the total number of nodal points is 11448 and the total number of elements is 13776 .

\subsection{Dynamic model of interaction force between wheel and rail}

Figure 5 shows a wheel/rail model. We focused on relative displacement between the wheel and the rail. The vertical interaction force of these components was modeled by Hertzian contact springs so that it can be possible to judge the contact condition between the wheel and rails. The vertical relative displacement between the rail and the wheel $\delta_{z}$ is expressed by equation (1).

$$
\delta_{z}=z_{R}-z_{W}+e_{Z}+e_{z 0}(y)
$$

where $z_{R}$ is the rail vertical displacement, $z_{W}$ is the wheel vertical displacement, $e_{Z}$ is the vertical track irregularity. $e_{z 0}(y)$ is the amount of change of the wheel radius at the current contact point from initial wheel radius. When $\delta_{Z} \geq 0$, the wheel is in contact with the rail, and $\delta_{Z} \leq 0$, the wheel is out of contact with the rail. The z-direction interaction force $H$ produced due to the contact of wheel and rail is expressed by equation (2).

$$
H=H\left(\delta_{Z}\right)
$$

The interaction force in the horizontal direction is expressed as a creep force until the wheel flange touches the rail. After contact, the wheel load and horizontal pressure act on the rail, causing the rail crown to move in the horizontal direction. As a result, torsion of the rail occurs. The torsion resistance which is generated by the rail and the rail fastener is expressed by a spring element.

Figure 6 shows the track irregularity which was used for analysis. A $2 \mathrm{~m}$ wave length irregularity measured using a measuring device of length $1 \mathrm{~m}$ was set consecutively to the slab track on the structure to be analyzed. However, it is considered that the excitation force generated by a track displacement of the order of a wavelength of several meters will not be reproduced sufficiently. Consequently, a $10 \mathrm{~m}$ wave length irregularity was added to the $2 \mathrm{~m}$ wavelength irregularity measured on the slab track of a meter-gauge railway line, although it was not on the structure to be analyzed, thus a long wavelength component was added. The pseudo peaks due to the measurement wavelength was removed using a filter.

\subsection{Numerical analysis method}

In order to carry out efficient numerical analysis, the equation of motion concerning the vehicle, track and structure was modal-converted. The resulting equation of

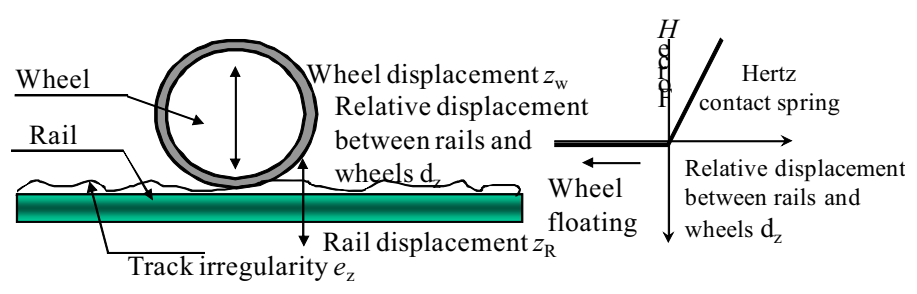

Figure 5. Wheel/rail model (vertical direction)

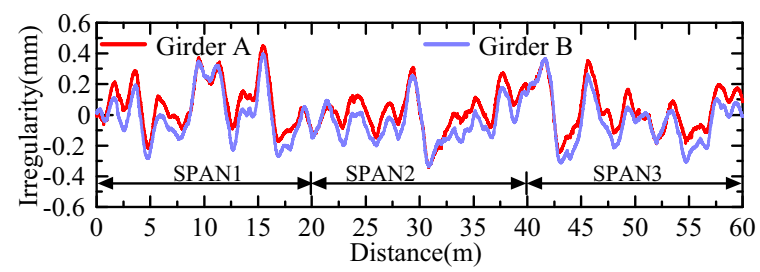

Figure 6. Track irregularity

Table 2. Analysis Case

\begin{tabular}{|c|c|c|}
\hline CASE & $\begin{array}{c}\text { Spring constant of } \\
\text { Track Pads } \\
(\mathrm{MN} / \mathrm{m})\end{array}$ & $\begin{array}{c}\text { Spring constant of Resilient } \\
\text { Materials } \\
(\mathrm{MN} / \mathrm{m})\end{array}$ \\
\hline $\mathrm{A} 1$ & 60 & $3.5 \mathrm{kN} / \mathrm{mm}^{2}(\mathrm{CA}$ mortar $)$ \\
\hline B1 & 30 & $3.5 \mathrm{kN} / \mathrm{mm}^{2}(\mathrm{CA}$ mortar $)$ \\
\hline $\mathrm{A} 2-1$ & 30 & $3.5 \mathrm{kN} / \mathrm{mm}^{2}(\mathrm{CA}$ mortar$)$ \\
\hline $\mathrm{A} 2-2$ & 20 & $3.5 \mathrm{kN} / \mathrm{mm}^{2}(\mathrm{CA}$ mortar $)$ \\
\hline AE-1 & 60 & $\begin{array}{c}2.4 \\
\text { (Rectangular solid test } \\
\text { piece of } 100 \times 100 \times 25 \mathrm{~mm})\end{array}$ \\
\hline $\mathrm{AE}-2$ & 60 & 0.6 \\
\hline $\mathrm{AE}-3$ & 60 & 0.15 \\
\hline
\end{tabular}

motion on the modal coordinate system of the vehicle and structure was progressively solved in time increment $\Delta t$ units by using the Newmark mean acceleration method. However, because the equation of motion is non-linear, iterative calculation has to be carried out within $\Delta t$ until the disproportional part becomes sufficiently small. The mode order in the analysis was set to a value that enabled vibration to about $400 \mathrm{~Hz}$ to be reproduced, and the analysis time step was set to $0.0005 \mathrm{sec}$. The frequency analysis was set to 4096 points (Observation time, approx. 2 seconds, $\Delta f=0.49 \mathrm{~Hz}$ ).

\subsection{Analysis cases}

Table 2 shows analysis cases. We carried out parameter studies for reinforced concrete girder. We paid attention to the various track parameters. CASE A1 and CASE B1 is the basic case. Although Girder A and Girder B are exactly same structures, only the spring constant of track pad is different. Girder A is $60 \mathrm{MN} / \mathrm{m}$ and Girder B is $30 \mathrm{MN} / \mathrm{m}$. Because each parameter is affected by the train speed, we calculated at $10 \mathrm{~km} / \mathrm{h}$ intervals over the range between 160 and $370 \mathrm{~km} / \mathrm{h}$.

CASE A2-1 and CASE A2-2 are changed the spring constant of $30 \mathrm{MN} / \mathrm{m}$ and $20 \mathrm{MN} / \mathrm{m}$, respectively. CASE AE-1, CASE AE-2 and CASEAE-3 are vibrationreducing track. CASE AE-1 corresponds to the Type $\mathrm{G}$ vibration reducing track, which are used in operation lines in Japan. 


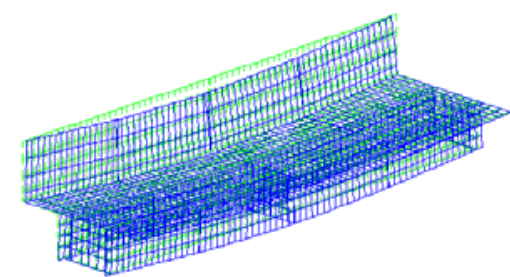

(a) $7.1 \mathrm{~Hz}$

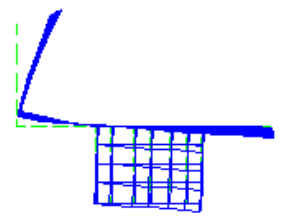

(b) $10.1 \mathrm{~Hz}$

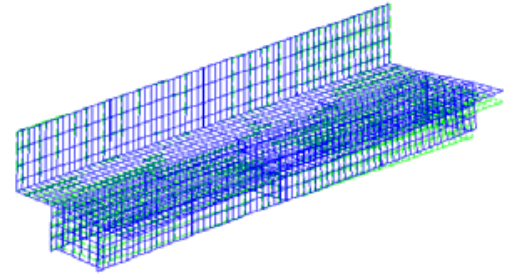

(c) $12.2 \mathrm{~Hz}$

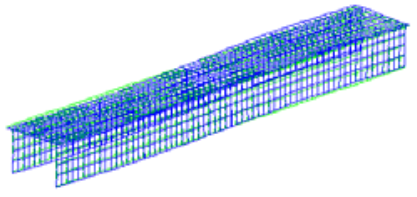

(d) $24.2 \mathrm{~Hz}$

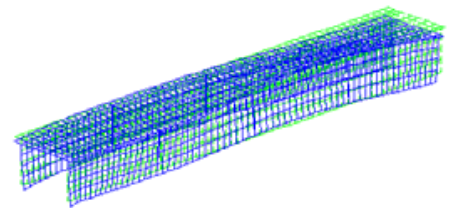

(e) $29.7 \mathrm{~Hz}$

Figure 7. Vibration modes of RC girder
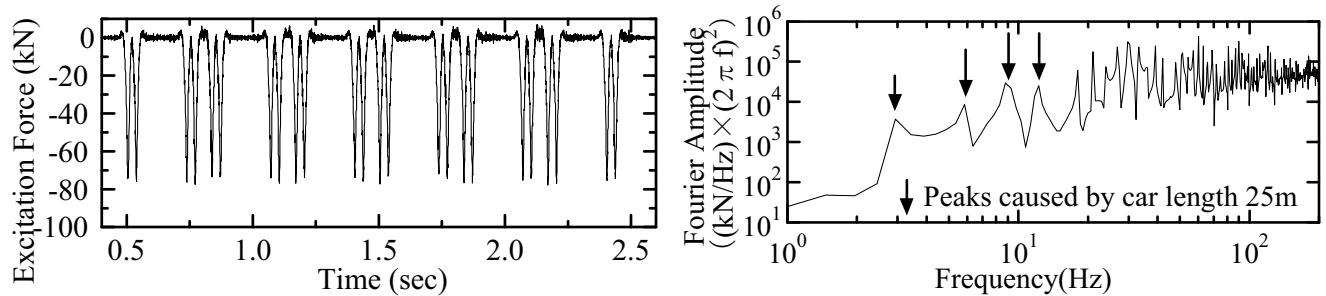

Figure 8. Time history wave and Fourier amplitude of excitation force $(270 \mathrm{~km} / \mathrm{h})$

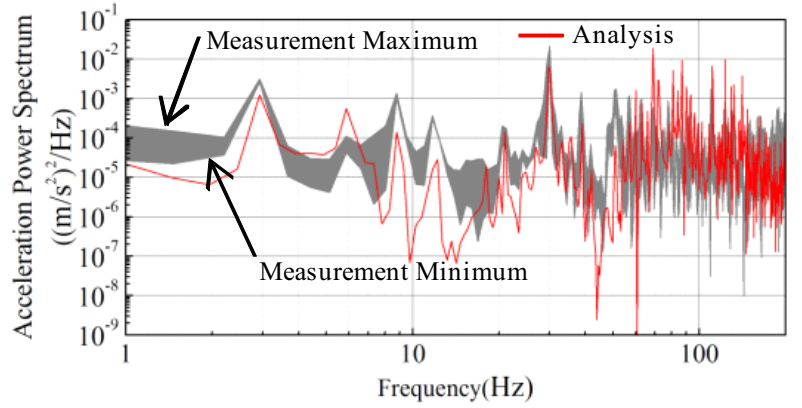

(a) Center slab

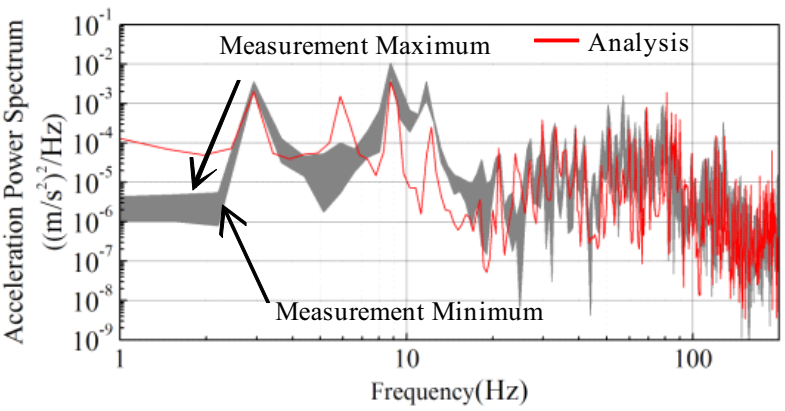

(b) Cantilever slab

Figure 9. Comparison between measurement and analysis concerning the frequency analysis results of the response acceleration of RC Girder A (CASE A1 270km/h)

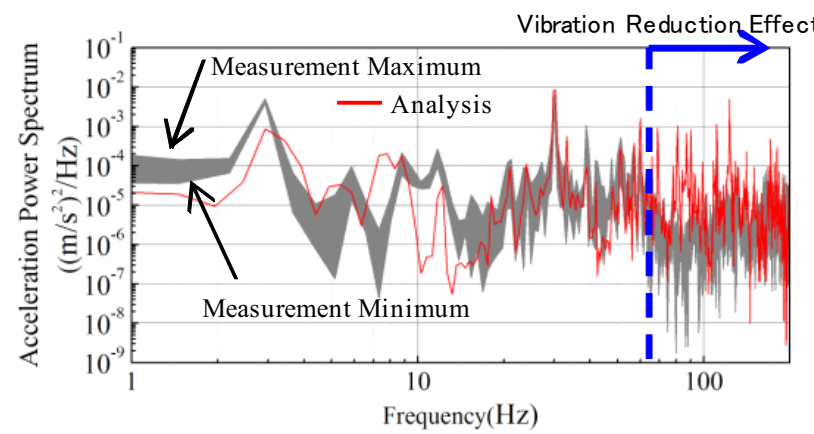

(a) Center slab

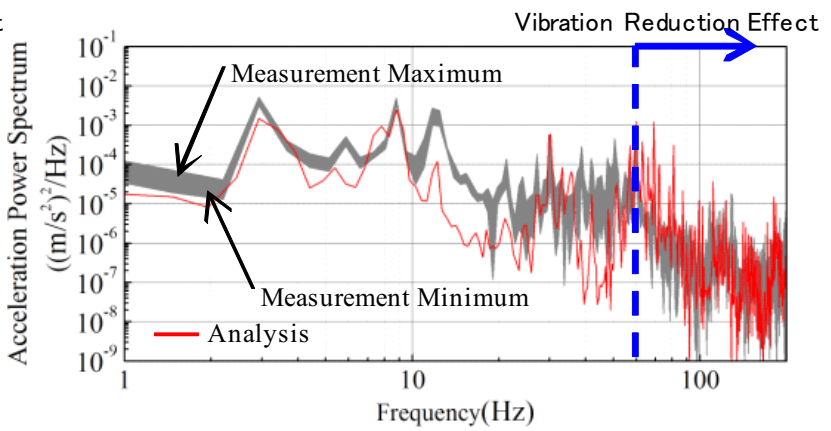

(b) Cantilever slab

Figure 10. Comparison between measurement and analysis concerning the frequency analysis results of the response acceleration of RC Girder B (CASE B1 270km/h)

\section{Analysis results}

\subsection{Vibration modes}

Figure 7 shows the vibration modes and natural frequencies of the RC girder. The first vibration mode of girder appears at $7.1 \mathrm{~Hz}$ and that of cantilever slab appears at $10.1 \mathrm{~Hz}$. Reference [6] provides a detailed report concerning validation of these vibration modes by measurement. We considered that analysis results accorded with measurement to some extent.

\subsection{Characteristics of excitation force}

Figure 8 shows the results of time history wave and frequency analysis for the spring reaction force of a single spring element equivalent to $\mathrm{CA}$ mortar in a 
vehicle/track system model. The train speed is $270 \mathrm{~km} / \mathrm{h}$. From the time waveform, it can be seen that a response peak appears each time an axle passes the spring element. It can be seen that a peak occurs at an integral multiple of the basic acceleration frequency $(3 \mathrm{~Hz}=(270 / 3.6) / 25)$ which is determined based on a train speed of $270 \mathrm{~km} / \mathrm{h}$ and a carriage length of $25 \mathrm{~m}$.

\subsection{Frequency characteristics of each member}

Figures 9 and 10 show a comparison between measurement and analysis concerning the frequency analysis results of the response acceleration at the center slab and cantilever slab of RC girder. The train speed is $270 \mathrm{~km} / \mathrm{h}$, and the reference points are the positions shown in Figure 2 (b). We decided to compare the results of measuring about 10 trains (the number of trains differs for each member) with the analysis results.

The above figure shows that a peak appears at an integral multiple of the basic excitation frequency $(3 \mathrm{~Hz}$ $=1 /(25 / 270 / 3.6)$ determined by the train speed and the carriage length.

When comparing measurement and analysis results, the analysis results are roughly within the range of random variation of the measurement results, for each member. In this way, analysis method we have developed, it was confirmed that it is possible to reproduce the actual dynamic response of RC girder member vibration.

When comparing Girder A in Figure 9 and Girder B in Figure 10, in the frequency band above about $70 \mathrm{~Hz}$, vibration reduction effect of soft track pad of $30 \mathrm{MN} / \mathrm{m}$ is recognized.

Figure 11 shows the influence on the acceleration response at the center slab by the difference of spring constant of track pads. This figure shows only analysis results. Vibration reduction effects of soft track pad are the almost same tendency as the results of Figure 9 and Figure 10 which is measurement results.

\subsection{Influence of spring constant of resilient materials of vibration reducing track}

\subsubsection{Natural frequency of vibration-reducing tracks}

Table 3 shows the natural frequencies of each track of first vibration mode. It can be seen that natural frequency of the track is lowered by the elastic support with resilient materials.

\subsubsection{Excitation force}

Figure 12 shows the frequency characteristics of excitation force. Train speed is $270 \mathrm{~km} / \mathrm{h}$. It can be seen that there is no significant difference in each excitation force by approximately $12 \mathrm{~Hz}$. In the frequency above $12 \mathrm{~Hz}$, excitation force is increased compared with CASE $\mathrm{A} 1$, at the vicinity of each natural frequency. And in the frequency above each frequency, excitation force is decreased with CASE A1.

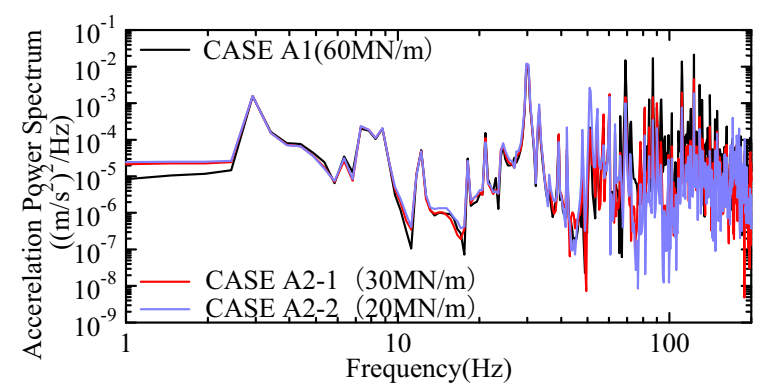

Figure 11. The influence on the acceleration response at the center slab by the difference of spring constant of track pads $(270 \mathrm{~km} / \mathrm{h})$

Table 3. Natural frequency

\begin{tabular}{|c|c|c|}
\hline CASE & $\begin{array}{c}\text { Spring constant of Resilient } \\
\text { Materials }(\mathrm{MN} / \mathrm{m})\end{array}$ & $\begin{array}{c}\text { Natural frequency } \\
(\mathrm{Hz})\end{array}$ \\
\hline $\mathrm{A} 1$ & $3.5 \mathrm{kN} / \mathrm{mm}^{2}(\mathrm{CA}$ mortar $)$ & 650 \\
AE-1 & $\begin{array}{c}2.4 \\
(\text { Rectangular solid test piece } \\
\text { of } 100 \times 100 \times 25 \mathrm{~mm})\end{array}$ & 57.8 \\
\hline AE-2 & 0.6 & 28.2 \\
\hline AE-3 & 0.15 & 14.0 \\
\hline
\end{tabular}

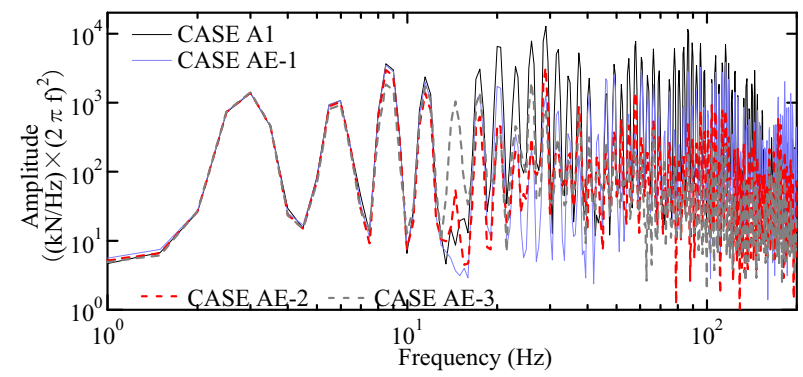

Figure 12. Frequency characteristics of excitation force $(270 \mathrm{~km} / \mathrm{h})$

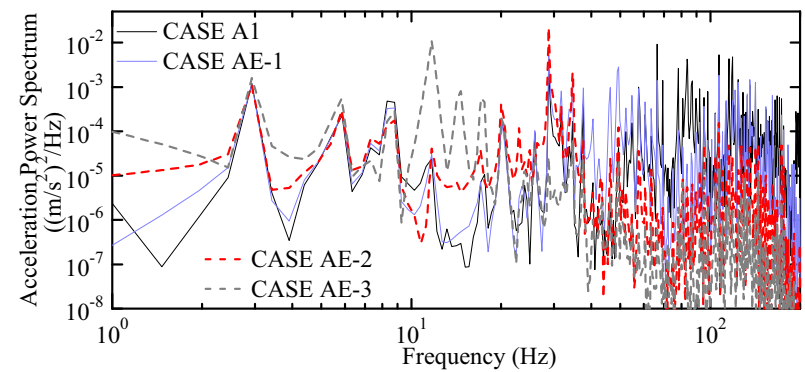

Figure 13. Frequency characteristics of acceleration response at the center slab

$(270 \mathrm{~km} / \mathrm{h})$

\subsubsection{Acceleration response at the center slab}

Figure 13 shows the frequency characteristics of acceleration response at the center slab. Train speed is $270 \mathrm{~km} / \mathrm{h}$. Similar to the excitation force in the figure 12 , excitation force is increased compared with CASE A1, at the vicinity of each natural frequency. And in the frequency above each frequency, excitation force is decreased with CASE A1. In this way, the frequency band which obtained reduction effect depends a great deal on natural frequency of vibration-reducing track. 


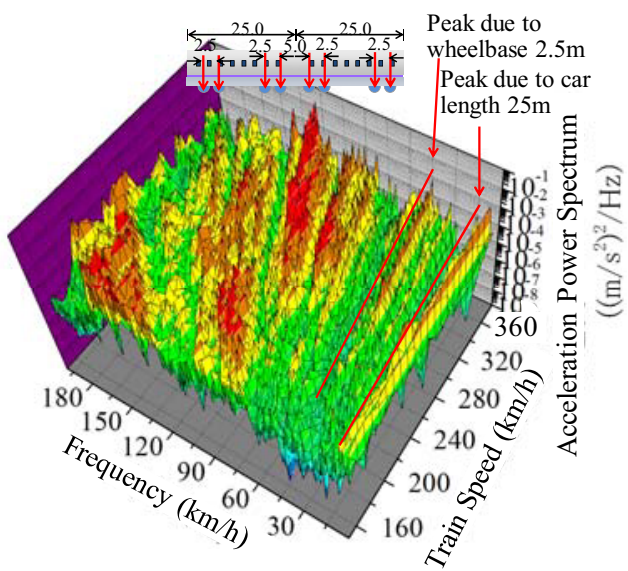

(a) CASE A1

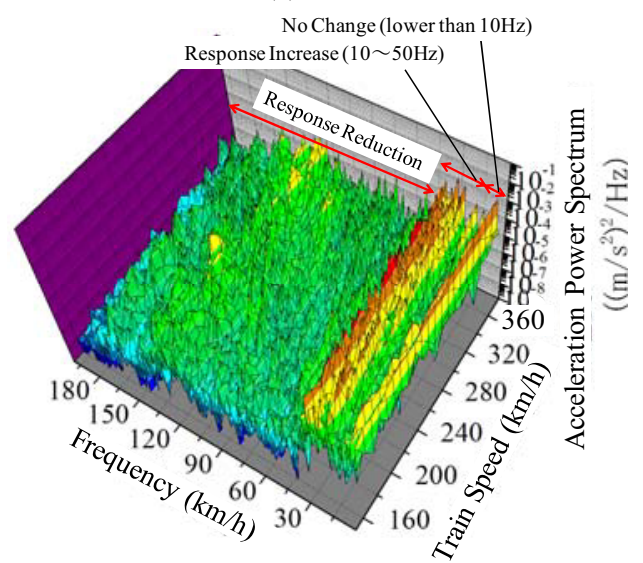

(c) CASE AE-2

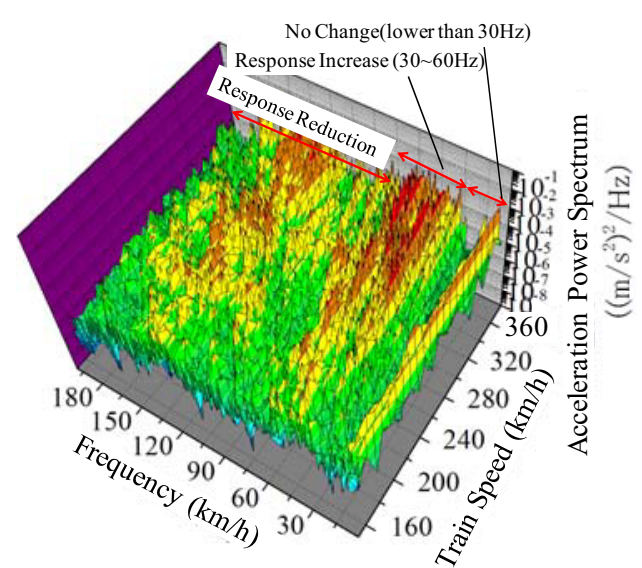

(b) CASE AE-1

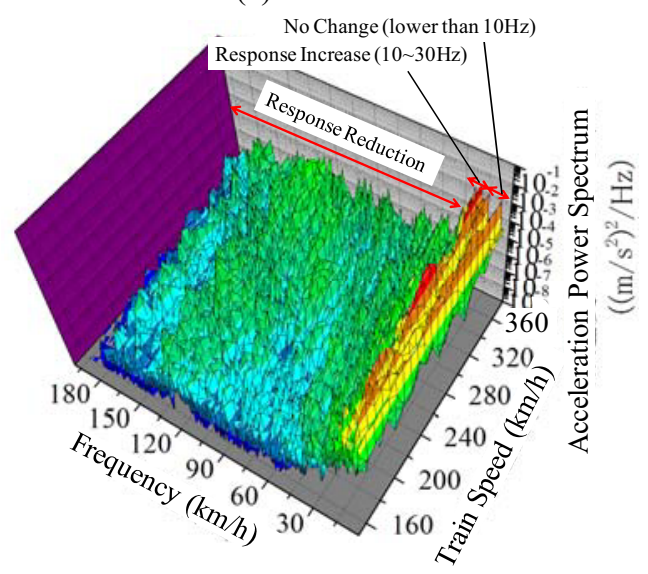

(d) CASE AE-3

Figure 14. The influence on the acceleration response at the center slab by the differences train speed and spring constant of track pads

Figure 14 shows the influence on the acceleration response at the center slab by the differences of train speed and spring constant of track pads. Train speeds are $160 \sim 370 \mathrm{~km} / \mathrm{h}$. In the response peak caused by car length $25 \mathrm{~m}$, it can be seen that there are no significant differences at the each CASE. Similar to the excitation force in the figures 12 and 13, excitation force is increased compared with CASE A1, at the vicinity of each natural frequency. In the frequency above each frequency, excitation force is decreased with CASE A1. As previously mentioned, it is said that in the case of a high-speed railway the dominant zone about structure borne sound lies between 30 and $100 \mathrm{~Hz}$. So, in order to obtain a reduction effect in this frequency band by vibration-reducing track, it is necessary to lower the natural frequency to CASE AE-3.

However, these results are based on numerical experiments. So it is necessary to study furthermore about feasibility in the actual track, from the various points of view about strength and durability of the resilient material, train running safety and construction ability.

\section{Conclusion}

The Knowledge obtained in this research is summarized below.
(1) It is confirmed that the proposed analysis method is useful to simulate the actual dynamic response of $\mathrm{RC}$ girder members.

(2) Vibration reduction effect of soft track pad of $30 \mathrm{MN} / \mathrm{m}$ is recognized in the frequency band above about $70 \mathrm{~Hz}$ by measurement results and analysis results.

(3) The frequency band in which reduction effect can be obtained depends a great deal on natural frequency of vibration-reducing track.

\section{References}

1. T. Watanabe, M. Sogabe, T. Yamazaki : A Study of Running Safety and Ride Comfort of Floating Tracks for High-Speed Train, Journal of Mechanical Systems for Transportation and Logistics, Vol.1, Issue 1, pp. 22-30 (2008)

2. T. Watanabe, M. Sogabe, M. Tokunaga, Analytical Study of Structural Member Vibration Characteristics of Reinforced Concrete Rigid Frame Viaduct, Quarterly Report of RTRI 55(3), pp.176183 (2014)

3. H. Wakui, N. Matsumoto, M. Tanabe, A Study on Dynamic Interaction Analysis for Railway Vehicle and Structures, Quarterly Report of RTRI, 35(2), pp.96-104, (1994) 
4. M. Tanabe, N. Matsumoto, H. Wakui, M. Sogabe, Simulation of a Shinkansen train on the railway structure during an earthquake, Japan Journal of Industrial and Applied Mathematics, 28-1, pp.223236, (2011)

5. M. Sogabe, N. Matsumoto, Y. Fujino, H. Wakui, M. Kanamori, M. Miyamoto, Dynamic Response and Design of Continuous Concrete Railway Bridges in Resonance Area, Journal of Japan Society of Civil Engineers, 724, pp.83-102, (2003)

6. K. Matsuoka, K. Kaito, T. Watanabe, M. Sogabe, Identification of High-Order Local vibration Properties of RC Viaduct under the Passing Train Loads, Journal of Japan Society of Civil Engineers, 67:3, pp.545-564, (2011) 